\title{
EMPODERAMENTO FEMININO E LITERATURA: UMA PROPOSTA DIDÁTICA PARA O ENSINO
}

\author{
Women's empowerment and literature: a didatic proposal for teaching
}

\section{Maria da Conceição Macedo de Freitas}

(iD) https://orcid.org/0000-0002-2221-9279

Secretaria de Educação e da Ciência e Tecnologia do Estado da Paraíba, Escola Estadual de Ensino Fundamental e Médio Professora Margarida Remígio Loureiro, Emas, PB, Brasil.

58763-000 -dipro.educacaopb@gmail.com

Resumo: A literatura na matriz curricular, no atual modelo brasileiro de educação, precisa contemplar a dupla função de formar o leitor literário e o cidadão crítico e receptivo às mudanças sociais e às diferenças de gênero. Diante disso, surge a singular necessidade da abordagem do feminismo na educação básica, a fim de disseminar a ideia de desconstrução de preconceitos preestabelecidos com relação à mulher na sociedade tradicional e patriarcal. Assim, por meio de pesquisa bibliográfica e interventiva, este trabalho tem o objetivo de apresentar às comunidades acadêmica e educacional abordagens metodológicas e literárias, que oportunizem a relação literatura e leitor, destacando a temática empoderamento feminino para o trabalho docente que fomente a formação do leitor literário. É intento desta pesquisa, ainda, discutir sobre o empoderamento feminino, bem como o papel e o espaço da mulher na história do Brasil, e na literatura clássica e contemporânea. O resultado desta pesquisa é a proposta didática apresentada que, por sua vez, torna-se uma alternativa para a formação do leitor, quando, a partir de uma mediação professoral adequada aos objetivos pretendidos e por meio de literatura feminina clássica e contemporânea, fomente nos estudantes o desejo da leitura literária.

Palavras-chave: Empoderamento feminino. Literatura. Sequência didática.

Abstract: The current literature curriculum in Brazilian schools needs to contemplate the dualpurpose of forming an integral literary reader as well as an open-minded citizen to social changes and gender differences. In order to spread the idea of deconstructing prejudices towards women in our traditional patriarchal society, the necessity of approaching feminism in basic education arises. Thus, through bibliographic and interventional research, this paper aims to present to the academic and educational communities a didactic material which links literature and women's empowerment as an approach to teach literature in high school. This paper also discusses women's empowerment, their role and space throughout the history of Brazil as well as in classic and contemporary literature. The result of this research is the didactic proposal presented, which, in turn, becomes an alternative for the formation of the reader, when, from a

Esta obra está licenciada sob uma Creative Commons - Atribuição 4.0 
teacher mediation adequate to the intended objectives and through classic and contemporary female literature, fosters students the desire for literary reading.

Keywords: Women's empowerment. Literature. Teaching material.

\section{Introdução}

O modelo brasileiro atual de educação transcende (ou deveria transcender) a aquisição e construção de conhecimentos dos estudantes. De fato, com as radicais e importantes mudanças que a sociedade hodierna enfrenta, o trabalho transdisciplinar e temático no currículo escolar é um caminho para a formação de cidadãos críticos às diferenças e receptivos a transformações.

Nesse contexto, a literatura na escola se destaca pela função social de manifestar leituras de mundo de diferentes ângulos, a fim de construir espaços de discussão que desenvolvam a criticidade do leitor, a partilha de suas experiências de leitura literária, bem como da reflexão de sua própria identidade. Assim, por meio da leitura subjetiva do texto literário, na qual o leitor se apropria do texto para (re)construir sua identidade, (ROUXEL, 2013) e da leitura compartilhada, vivenciada e socializada, estabelecendo pontes do individual ao coletivo (COLOMER, 2007), através da contextualização temática do processo metodológico de letramento literário (COSSON, 2014), o professor de literatura se apropria de abordagens didático-metodológicas para o trabalho com o texto literário na escola que preconize o principal objetivo da literatura na matriz curricular: a formação do leitor literário.

Sendo assim, essa formação do leitor implica também na construção do cidadão crítico, sensível a sua realidade e de outrem, tendo em vista a função de arte humanizadora da literatura na escola (CANDIDO, 2004). A partir desse entendimento e do atual cenário da luta das mulheres no espaço sócio-político, o termo empoderamento feminino tem tomado proporções acentuadas nos estudos acadêmicos, uma vez que se trata do processo de autonomia e independência das mulheres nos âmbitos político, social, educacional, artístico, cultural, entre outros.

Nessa lógica, as dificuldades docentes no trabalho com as questões de gênero na escola refletem a sociedade conservadora e machista, ainda no século XXI, que desvirtua o papel feminino na família, e, mais ainda, na sociedade, na política, na cultura, nas artes, em todos os espaços possíveis e (in)acessíveis à mulher. $\mathrm{O}$ trabalho com o texto literário permite, portanto, além da formação do leitor literário, o espaço de discussão para a desmistificação da representação tradicional da feminilidade na sociedade atual, o que pode gerar resistências aos mais conservadores.

A ideia do trabalho sobre feminilidade e empoderamento por meio da literatura surgiu durante a pesquisa interventiva de trabalho dissertativo de mestrado da autora, a fim de formar leitores literários na escola, quando as questões referentes às desigualdades de gênero emergiram, ainda que a intenção didático-pedagógica dos textos não fosse essa. Surgiu, portanto, o desejo de refletir, ainda mais, a temática por meio da leitura e do trabalho com o texto literário. Assim, esta pesquisa recorre à temática empoderamento feminino, uma vez que o termo contempla o tratamento das questões de gênero e se justifica pelo seu conceito e 
receptividade para as discussões em sala de aula.

Para além, acreditamos, portanto, que a ação docente direcionada pelo letramento literário, como abordagem metodológica que facilita a formação do leitor, a partir da centralidade do texto literário e de sua relação temática com o empoderamento feminino, resulta na reconstrução ideológica e identitária do leitor em formação, na medida em que esse se posiciona no lugar do outro e se aproxima de suas experiências.

Assim, este artigo objetivou a construção de uma sequência didática que contextualizasse tematicamente o empoderamento feminino, a partir da leitura de contos contemporâneos e clássicos, à luz do letramento literário (COSSON, 2014), como procedimento metodológico para a formação do leitor. Foi intento deste trabalho também refletir o empoderamento feminino como um processo de ruptura da opressão patriarcal no meio artístico-literário e político-social, a fim de compreender como se sucedeu (e ainda se sucede) a luta feminina pelos direitos de igualdade e equidade.

Quanto às vias metodológicas, o estudo percorreu as seguintes etapas: 1) pesquisa bibliográfica - levantamento de aporte teórico-metodológico referente aos estudos acerca do empoderamento feminino, seleção e análise do corpus desta pesquisa: textos literários contemporâneos e clássicos, especialmente contos, que abordem o empoderamento feminino; 2) pesquisa interventiva - produção de sequência didática para a formação do leitor literário, crítico e humanizado como uma proposta alternativa para o trabalho temático com o texto de literatura, aportado pelo letramento literário, como procedimento metodológico, que fomenta a leitura literária e a contextualização temática para a formação do leitor.

Confiamos na formação do leitor a partir da efetiva leitura literária do texto em sala (BRASIL, 2006; COSSON, 2014), bem como do trabalho por meio de oficinas que abordem o empoderamento feminino, para a desconstrução de preconceitos e disseminação da igualdade de gêneros na sociedade contemporânea, a fim de despertar o processo de humanização do leitor (CANDIDO, 2004). Para tanto, acreditamos que o letramento literário consiste numa abordagem para o ensino que contempla os objetivos do trabalho docente para a formação do leitor de literatura na escola.

Por fim, reiteramos o papel da literatura como via própria para o entendimento das culturas e das sociedades, que se destaca pelo seu papel individual, subjetivo, mas também social e político, para formar, além de leitores literários, cidadãos críticos e transigentes às diferenças entre os gêneros.

\section{Fundamentação metodológica: contexto, natureza e procedimentos da pesquisa}

A ação científica se constitui de pré-determinadas padronizações dos diversos modos de pesquisa e atuação do pesquisador no meio onde vive. Decerto, a ciência atua na possibilidade de investigação para o conhecimento e/ou para a proposta de mudanças necessárias em diferentes espaços da sociedade, inclusive no meio educacional.

Desse modo, é necessária e fundamental a atuação do professor-pesquisador, que, à luz de seus estudos acadêmico-científicos, deseja transformar os resultados de sua realidade 
educacional com sua práxis, na sala de aula, por meio da prática das teorias pedagógicas estudadas nas academias. Embasados nessa máxima, pretendemos, neste espaço, apresentar, em síntese, como se efetivou o estudo apresentado.

De natureza bibliográfica, uma vez que alguns dos dados e informações coletados já existem e serviram de base teórica para análise e interpretação (LEITE, 2008) esta pesquisa precisou recorrer a fontes confiáveis, com idoneidade científica comprovada. As pesquisas e os estudos históricos acerca do empoderamento feminino auxiliaram o aparato contextual desta pesquisa.

A segunda etapa da pesquisa referiu-se ao processo de seleção e estudo dos textos literários e das atividades de leitura que constituíram o repertório de leituras da sequência didática. Quanto a essa seleção, a escolha pela associação de contos contemporâneos e canônicos se fundamentou na possibilidade do trabalho promissor para a formação do leitor por meio de textos diversos e atuais, ainda que clássicos e escritos cronologicamente há vários anos, uma vez que, os textos literários com linguagem e temática atrativas aos novos leitores, por meio de uma abordagem docente que aproxime a obra ao leitor, a receptividade da proposta pelos estudantes é maior, bem como a interação destes em todo o processo didático.

A proposta didática produzida neste trabalho, tendo em vista a formação do leitor, pelo letramento literário, também recorreu às teorias da Estética da Recepção (JAUSS, 1994; BORDINI; AGUIAR, 1988), no que se refere ao atendimento ao horizonte de expectativas de leitura dos estudantes de Ensino Médio, não leitores de literatura brasileira, com poucas experiências literárias, a partir de textos literários que tratassem o empoderamento feminino.

Para tanto, a fim de estruturar a proposta didática sugerida, tomamos os estudos de Zabala (1998) e Dolz (2004) quanto à sequência didática, isto é, um conjunto de atividades escolares, organizadas sistematicamente, em torno de um gênero textual. Os escritores corroboram uma estrutura base de trabalho didático que inicie e finalize as ações pedagógicas com a leitura, $o$ estudo e a produção de texto. De modo particular, neste trabalho, desejamos construir uma sequência didática que, a partir do gênero literário conto e da temática empoderamento feminino, aproxime o estudante ao hábito de leitura literária, na exploração temática dos textos e da literariedade da obra, favorecendo a formação do leitor crítico.

\section{Empoderamento feminino: a voz das mulheres na literatura}

As discussões que norteiam a participação feminina nos espaços sociais têm tomado vastas proporções para o debate sobre questões de feminilidade e representatividade da mulher. Isto se sucede porque, em pleno século XXI, a busca feminina pela igualdade de direitos e de espaços na sociedade hodierna ainda é uma realidade para aquelas que, ao longo de muitos anos, permaneceram mudas, às margens de uma civilização patriarcal e opressora.

A ideia da mulher subordinada ao homem, mulher do lar, mulher mãe, tem embasamento ancestral. Embora o Brasil seja um país democrático oficialmente, em que todos são iguais perante a lei, essa compreensão feminina de posição secundária na sociedade, perpetuada ainda em tempos modernos, está muito solidificada na sociedade patriarcal, na qual o homem é o 
responsável pela prole e a mulher, ainda que trabalhe e financeiramente participe ativamente das atividades de casa, recebe o papel de ajudante. Sendo assim, cabe ao homem o exercício do poder e da conquista do mercado de trabalho (CARVALHO, 2016).

A naturalização do papel secundário da mulher, bem como seu silêncio na história, ocultou a importância da efetiva participação de muitas mulheres na trajetória política do Brasil, escusa em personalidades masculinas. Carvalho (2016), em seu trabalho Trajetória de empoderamento político da mulher brasileira, lembra diversas mulheres que, acompanhadas ou não de figuras masculinas, envolveram-se na área política do país, a fim de transformar esse cenário brasileiro, porém foram esquecidas pela sociedade.

Mulheres como Tereza de Benguela, líder do quilombo do Quariterê, após a morte de seu esposo, José Piolho; Hipólita Jacinta, participante das manifestações da Inconfidência Mineira; Maria Quitéria de Jesus, primeira mulher a alistar-se como homem no Regimento de Artilharia para lutar contra a tropa portuguesa quando era proibida a participação feminina em guerras; Nísia Floresta Augusta, primeira mulher a defender a emancipação feminina, por meio da publicação de artigos em jornais de grande circulação no país; Maria Firmina dos Reis, primeira mulher a publicar um romance brasileiro, Úrsula, em 1859; Celina Guimarães Viana, primeira mulher a votar no Brasil, em 1927; e Dilma Rouselff, primeira mulher presidenta do Brasil; representam o consistente e permanente envolvimento feminino na política, pretendendo o direito da igualdade de gênero neste espaço social (CARVALHO, 2016).

Diante desse cenário, percebemos que a luta feminina não é atual. A mulher contemporânea apenas sucede um trabalho - ocultado propositalmente pela sociedade machista e tradicional - iniciado há muitos anos por outras mulheres, que sofreram rejeições e preconceito pela postura de empoderamento e emancipação que pretendiam alcançar.

Sobre empoderamento, ainda que o vocábulo não tenha sido dicionarizado em Língua Portuguesa no Brasil, constituindo-se um neologismo, trata-se do "processo da conquista da autonomia, da auto-determinação" (SARDENBERG, 2016, p. 2) de alguém que se encontra à margem do poder. Um processo que compreende o meio e instrumento para e o fim em si mesmo. Sendo assim, o empoderamento é a ruptura da dominação e/ou subordinação de alguém sobre outrem. No que diz respeito ao empoderamento feminino, este processo consiste "na libertação das mulheres das amarras da opressão de gênero, da opressão patriarcal" (SARDENBERG, 2016, p. 2), implicando, dessa forma, "na perda da posição de privilégio concedido aos homens pelo patriarcado" (BATLIWALA, 1994, p. 131). Assim, é possível dizermos que o empoderamento feminino é necessário para homens e mulheres na busca de uma sociedade igualitária e tolerante no que se refere às diferenças de gênero. No entanto, é um processo lento que precisa resistir às frentes tradicionais que o rejeita.

De fato, o empoderamento, para as feministas, tem o objetivo de discutir a ideologia patriarcal, a fim de alterar as instituições conservadoras que propagam as desigualdades sociais e, em particular, a discriminação de gênero, além de oportunizar condições para as mulheres terem acesso a recursos materiais e informacionais, de modo a gozar de sua autonomia e independência (SARDENBERG, 2016). Desse modo, diante de sua própria realidade, as 
mulheres entendem que têm direito à igualdade, à dignidade, à justiça, à participação na política e no mercado de trabalho, às ciências e às artes.

Decerto, a inserção e aceitação da autoria feminina nas artes e, em especial, na literatura não foi (ou está sendo) um processo fácil e simples. Se analisarmos, rapidamente, os cânones da literatura brasileira, perceberemos que, em sua maioria, foram e ainda são homens aqueles consagrados pela crítica literária como bons, o que atualmente é questionado por diversas escritoras, tendo em vista a influência e soberania masculina em detrimento da participação tímida e contida das mulheres na literatura ao longo dos anos (BARATA, 2015); perceberemos que a literatura clássica está mais sensível ao cotidiano e aos interesses da elite brasileira, estabelecida aos moldes europeus e norte-americanos (MESQUITA; DIAS, 2017), implicando, assim, na pouca representatividade das minorias, em particular para este trabalho, da mulher empoderada que usa a literatura, meio até então masculino, para escrever sobre e para a mulher, em estilo e linguagem próprios, a fim de externar suas lutas, seus desejos, seus sentimentos, suas angústias e seus medos.

Assim, alguns nomes femininos na literatura precisam ser lembrados, a fim de se entender como as autoras tratam o empoderamento feminino em seus escritos e em suas personagens. Uma destas mulheres empoderadas e imersas na literatura é Conceição Evaristo, que

[...] além de remeter à cultura negra, apresenta a dura vivência do negro no meio social. De forma específica, Conceição Evaristo utiliza-se da literatura para exaltar a mulher negra, contradizendo o senso comum que muitas vezes a retrata como um ser sem qualidades, que não tem esclarecimento e é fadado ao subemprego (MESQUITA; DIAS, 2017, p. 166).

Desse modo, Evaristo apresenta à arte o feminismo negro, isto é, a independência das mulheres negras, a partir de personagens que manifestem suas experiências de opressão e de liberdade, sua visão de mundo e de si mesma, a partir do lugar que ocupam. Evaristo possibilita à mulher negra um espaço de empoderamento e de leitura própria por meio da leitura de personagens que vivem tudo aquilo que é cotidiano para as mulheres.

Paulina Chiziane, a primeira mulher moçambicana a publicar um romance, é também uma figura singular na representatividade feminina na literatura (SANTOS; MENDES, 2016). Suas lutas femininas na África e seus questionamentos acerca da cultura machista e conservadora de seu país, em que a poligamia é aceita e legal, acentuam a mulher empoderada e destemida que se posiciona no mundo masculino para manifestar a condição de subordinação da mulher africana. Como, em entrevista, Chiziane (2008, apud SANTOS; MENDES, 2016) discorre:

Ser mulher é muito complicado, e ser escritora é uma ousadia. Como é uma ousadia a mulher sair de madrugada, ir à praia comprar peixe para vir cozinhar. A mulher está circunscrita num espaço e quando salta essa fronteira sofre represálias [...] É sempre uma dificuldade, porque primeiro, eu tenho que provar que sou capaz, depois tenho de conquistar um espaço [...] (CHIZIANE, 2008 apud SANTOS; MENDES, 2016, p. 53)

A representação feminina na literatura tem, ainda, Marina Colasanti como expoente. De 
acordo com Enedir Silva Santos e Kelcilene Grácia-Rodrigues, seus contos "transitam entre o real e o fantástico alinhavando ações que conduzem as relações humanas e seus dilemas" (SANTOS; GRÁCIA-RODRIGUES, 2015, p. 160). É verdade que a apropriação da linguagem e dos interesses por questões de gênero de Colasanti aproximou os leitores contemporâneos que procuram novas leituras do mundo e do feminino, a fim da compreensão de muitas situações e ideologias atuais. Colasanti, em seus contos, questiona as estruturas sociais pré-concebidas, oportunizando à mulher o rompimento do comportamento estabelecido histórico e socialmente e a sensibilidade às novas experiências de liberdade e de poder feminino.

Sim, poder feminino. Poder que não é dado por sua própria voz, é reconhecido pelo outro, pela voz narrativa heterodiegética que contempla de longe a definição do ser mulher se estabelecendo nos mínimos detalhes narrativos, ora para solucioná-los, ora para modificar o rumo do que é narrado (SANTOS; GRÁCIA-RODRIGUES, 2015, p. 162).

Maria Valéria Rezende é outra escritora que propaga o empoderamento e representa a feminilidade na literatura. Suas obras e sua vida abordam as questões de religiosidade e feminismo, a fim de se apropriar de ambos sem rejeitá-los em suas discrepâncias. Rezende participa atualmente do projeto Mulherio das Letras, no estado da Paraíba, que, segundo ela, começou timidamente, mas que, com o passar dos anos, tomou espaço em outros estados brasileiros, bem como no exterior. Em uma entrevista, a escritora, sobre o feminismo, o projeto e o machismo, afirmou:

O Mulherio é uma resposta ao machismo no mundo dos livros. Já me aconteceu de estar em um evento literário e nenhum dos escritores me cumprimentar mesmo sabendo quem sou. São os mesmos que fazem o que chamo de "literatura da brochada". Os velhos, de mais de 60, criam personagens que ficam lembrando do atletismo sexual em todo o romance. É o mimimi deles. (REZENDE, 2018, n.p).

Decerto, poderíamos lembrar outros nomes de mulheres empoderadas que disseminaram (e ainda disseminam) a ideia do empoderamento a muitas outras mulheres, por meio de textos literários. No entanto, é preciso dar espaço maior à proposta didática que efetivamente busca tratar a mulher, a literatura e o ensino de modo integrado, a fim de desconstruir preconceitos e formar valores, ideias e identidades.

\section{Sequência didática: A mulher na literatura}

A proposta deste estudo foi construir uma sequência didática que oportunize o trabalho com o texto literário e o empoderamento feminino, a fim de formar o leitor literário crítico às diferenças e disposto ao respeito às diversidades de gênero. Como não foi nosso intento o relato de experiência da aplicação da sequência didática, dispusemo-nos a construir uma proposta didática para um público comum às escolas públicas brasileiras, com perfil de jovens não leitores de literatura clássica, mas que costumam ler obras de ficção, com linguagem acessível 
e de fácil compreensão ${ }^{1}$. Justificamos, na produção da sequência didática, a recorrência de textos contemporâneos, a fim de atender ao horizonte de expectativas de leitura dos estudantes. Os textos clássicos, por sua vez, foram escolhidos para a expansão do repertório de leituras literárias desses leitores.

Quanto ao número de aulas, a sequência didática foi planejada para 16 encontros, podendo acontecer em aulas geminadas e contínuas, como um projeto didático-pedagógico, em que as aulas de Língua Portuguesa de um mês letivo seriam utilizadas para este trabalho literário, considerando as quatro aulas semanais reservadas à disciplina Língua Portuguesa, no ensino médio. É possível, ainda, a aplicação da sequência didática no decorrer de dois bimestres letivos, com a disposição de uma aula semanal para o cumprimento da proposta.

A temática $A$ mulher na literatura foi desenvolvida, na proposta, por meio de subtemáticas, a saber: a) A mulher na literatura romântica; b) Contos de fadas e contos modernos; c) Comportamentos femininos em Marina Colasanti; d) A literatura e a mulher real; e) Conceição Evaristo e o feminismo negro; e f) Textos literários diversos de autoria feminina. Certamente, como se trata de uma proposta de trabalho alternativo para o ensino literário, nossa intenção não foi esgotar as inúmeras possibilidades de desenvolvimento metodológico, tampouco compreender, neste estudo, todos os textos literários que nos possibilitassem essa construção, portanto, a sequência didática proposta neste artigo trata-se de mais uma possibilidade de facilitar a leitura literária na sala de aula e fomentar a função social da literatura de descontruir preconceitos e formar uma sociedade sensível às diferenças de gênero.

\section{Subtemática 1. A mulher na literatura romântica}

A subtemática $A$ mulher na literatura romântica tem como objetivo discutir a posição e o comportamento femininos na estética artístico-literária Romantismo, considerando a voz restritamente masculina nos textos literários e poéticos que expressam os sentimentos e emoções da mulher, nascida e intencionalmente educada à vida limitada e reservada para o cumprimento de seu papel na família e na sociedade tradicional. É intenção dessa subtemática, ainda, a reflexão por meio dos textos literários sobre os abusos e as violências sofridas pelas mulheres nas poesias lidas.

Com a leitura dos poemas "É ela! É ela! É ela! É ela!" e "Soneto", de Álvares de Azevedo (1996); e "Leito de folhas verdes", de Gonçalves Dias (1959), o debate sobre a mulher ideal e idealizada, que ama, encanta, é amada e encantada, projetada para o homem, coloca em questão a insegurança de relacionamentos amorosos, bem como a sensualidade da mulher na relação sexual. Em duas aulas, a proposta de trabalho de leitura envolve, principalmente, a postura do homem que busca a mulher para se satisfazer afetivo e sexualmente, e a posição da mulher, que também deseja, mas que, em certos casos, se torna objeto de desejo e de satisfação masculina,

\footnotetext{
${ }^{1}$ Apesar de não oferecer um estudo amplo e detalhado sobre o perfil dos estudantes da educação básica brasileira quanto à leitura de textos literários neste trabalho, é lícito acentuar a ausência do hábito de leituras literárias canônicas entre os jovens estudantes. Sugerimos a leitura das pesquisas científicas de Maria da Conceição Macedo de Freitas (2018) e Gabriela Rodella de Oliveira (2013), como também o resultado da pesquisa Retratos da leitura no Brasil, organizada por Zoara Failla (2016).
} 
apenas.

Como procedimentos metodológicos, para a primeira aula, optamos pela leitura inicial, em voz alta, dos textos “É ela! É ela! É ela! É ela!" e "Soneto”, de Álvares de Azevedo (1996), seguida de debate sobre a postura dos personagens masculinos que assediam suas amadas, atentando-se aos fatos narrados nos textos poéticos quanto ao assédio em determinados toques e carícias na mulher.

A proposta de leitura para a segunda aula é a poesia "Leito de folhas verdes", de Gonçalves Dias (1959). Sugerimos, por meio do debate, o estudo do comportamento do eulírico feminino que deseja seu prazer sexual. Finalmente, a ideia de promover um diálogo acerca das características em comum dos textos românticos lidos, a fim de relacionar as personagens femininas nas poesias, fornecerá subsídios para o estudo dos elementos de literariedade dos textos, como também a promoção de leituras comparativas entre personagens. Esperamos, ainda, que as discussões propostas tragam à reflexão a sexualidade feminina bastante silenciada pela sociedade conservadora.

Para encerrar a subtemática, propomos a leitura do conto "Cinderela", como tarefa dos estudantes para casa. O objetivo dessa proposta é a continuidade da aula de literatura para além dos muros escolares, com a possível participação familiar, inclusive.

\section{Subtemática 2. Contos de fadas e contos modernos}

Ainda associando a postura tradicional da mulher à moderna postura feminina, a subtemática Contos de fadas e contos modernos, com a leitura dos textos "Cinderela" e "A moça tecelã", de Marina Colasanti (2010), provoca a reflexão acerca da atitude feminina quanto à sua vida, futuro, felicidade, uma vez que Cinderela e a moça tecelã divergem, radicalmente, quanto à tomada de decisão sobre o casamento, à responsabilidade de sua própria felicidade, à iniciativa de transformação de sua realidade atual para um futuro melhor. Com a leitura em casa do texto Cinderela, uma aula faz-se necessária para a leitura literária do conto de Colasanti (2010) e a análise comparativa das personagens femininas dos textos lidos.

O objetivo da subtemática é discutir a durabilidade do matrimônio e a postura da esposa no casamento, à medida que evidenciamos os comportamentos de Cinderela e da Moça Tecelã. A partir da leitura oral do texto de Colasanti (2010) e da retomada da leitura do conto "Cinderela", realizada em casa pelos estudantes, os leitores são convidados a apontarem as semelhanças e diferenças das personagens femininas dos contos lidos. É possível destacar também o posicionamento de submissão de Cinderela, quanto à concretização da sua felicidade apenas no matrimônio, em oposição à atitude empoderada da moça tecelã que, por sua vez, protagoniza sua história e seu relacionamento.

Como atividade extraclasse, sugerimos aos alunos a pesquisa do significado das palavras submissão e empoderamento, relacionando-as às personagens femininas dos contos lidos.

\section{Subtemática 3. Comportamentos femininos em Marina Colasanti}

Considerada um referencial da literatura feminina, Marina Colasanti expressa, em seus 
textos, os diversos comportamentos femininos no casamento. O objetivo dessa subtemática é o estudo das posturas divergentes das mulheres dos contos de Marina Colasanti (2010) na família tradicional e no relacionamento amoroso, bem como o reconhecimento das posturas de dominação masculina e submissão feminina entre as personagens dos contos lidos.

Os contos "Para que ninguém a quisesse", "Quando já não era mais necessário" e "Plano matrimonial" foram escolhidos porque revelam a postura de dominação masculina e submissão feminina no casamento, até que a mulher, por meio do empoderamento, ruptura essa condição de inferioridade e descontrói a visão indelével do matrimônio, em busca de sua felicidade plena. Nessa etapa da sequência, a visão de mulher subordinada à vontade de seu esposo é substituída pela mulher decidida, moderna, que deseja seu prazer sexual e afetivo, e não se restringe ao seu papel de satisfazer, mas que suplica sua própria satisfação. Em duas aulas, a proposta didática se desenvolve contemplando a ideia da mulher que pode se construir como desejar, ser o que ela quiser.

Na primeira aula, sugerimos a leitura do conto "Para que ninguém a quisesse", de Marina Colasanti (2010), e um rápido debate sobre a temática a partir do seguinte questionamento: $\mathrm{O}$ que faz uma mulher permitir situações de humilhação e alienação ao esposo? Essa provocação suscitará a leitura do conto "Quando já não era mais necessário", da mesma autora, realizada por um estudante. Em seguida, a reflexão da postura da mulher nessa narrativa em oposição à personagem do conto lido anteriormente, trará à tona os diversos posicionamentos femininos dentro do casamento.

$\mathrm{Na}$ segunda aula da subtemática, propomos a retomada do debate sobre a postura feminina moderna e espontânea, por meio da leitura do conto "Plano matrimonial", de Marina Colasanti (2010), referenciando a personagem que decide casar-se e escolhe seu esposo de acordo com sua vontade. Pensamos que, com as discussões, emergirão diversas opiniões quanto ao protagonismo e modernidade das personagens, em detrimento à visão patriarcal da mulher no relacionamento amoroso.

Finalmente, sugerimos aos alunos, como tarefa extraclasse, um trabalho de entrevista com as mulheres responsáveis por eles, a fim de conhecerem suas opiniões sobre a atitude (ou a falta dela) da personagem feminina do texto "Para que ninguém a quisesse", de Marina Colasanti (2010). Essa atividade intenta, mais uma vez, perpetuar a proposta literária escolar para o meio familiar, facilitando, dessa forma, a formação do leitor fora da escola.

\section{Subtemática 4. A literatura e a mulher real}

Para além do comportamento feminino na literatura, a temática $A$ literatura e a mulher real, em três aulas, intenta oportunizar o espaço para a voz feminina, a mulher real que fala sobre suas experiências de vida na família, na sociedade e no mercado de trabalho, ainda muito masculinizado.

Na primeira aula da subtemática, recomendamos a exposição dos resultados da atividade extraclasse solicitada aos alunos em aula anterior. Após o momento de socialização e partilha, sugerimos a leitura literária da poesia de Cora Coralina (2011), “Assim eu vejo a vida”, e a 
reflexão sobre a mulher real, não ficcional, que sofre violência e misoginia em sua vida cotidiana.

Nas duas aulas seguintes, propomos a leitura do testemunho de Paulina Chiziane (2013), Eu, mulher... por uma nova visão do mundo. Nesse texto, escrito em 1990, a escritora africana revela suas dificuldades e suas experiências negativas de discriminação e misoginia, num continente extremamente machista e tradicional. A leitura e a posterior reflexão sobre a temática podem favorecer a mudança de comportamentos machistas, inclusive em mulheres, por meio da desconstrução de preconceitos e formação de novas ideias e ideologias femininas.

A fim de concretização das discussões levantadas na sala de aula, a atividade extraclasse para essa subtemática é uma conversa/entrevista com uma profissional sobre as dificuldades enfrentadas por uma mulher no mercado de trabalho.

\section{Subtemática 5. Conceição Evaristo e o feminismo negro}

Com a escritora brasileira Conceição Evaristo, o feminismo negro foi difundido na literatura com maior representatividade. A sua obra Insubmissas lágrimas de mulheres expressa as dores, lutas e vivências de mulheres reais, que se dispuseram a contar-lhe suas histórias de vida, registradas na obra de Evaristo. Essa subtemática, portanto, objetiva introduzir os textos literários de Conceição Evaristo nas aulas de literatura brasileira, tendo em vista o feminismo negro como luta de direito de empoderamento das mulheres negras e revelando histórias de mulheres reais, por meio da autoria feminina.

A subtemática compreende a leitura e discussão de quatro contos de Insubmissas lágrimas de mulheres (2016), intitulados com os nomes das personagens femininas: "Aramides Florença", "Natalina Soledad", "Shirley Paixão" e "Adelha Santana Limoeiro". Apesar de a obra evaristiana constar de 13 histórias de mulheres reais e díspares, a escolha por quatro contos se deu pela adequação da sequência didática à realidade da sala de aula, bem como ao número disponível de aulas para essa proposta didática.

Para atividade de leitura, apostamos na partilha de experiência de leitura dos estudantes, quanto ao enredo e aos comportamentos femininos das protagonistas das narrativas literárias lidas, como também o debate sobre a misoginia e o racismo presentes nas estórias evidenciadas nas aulas.

Como atividade extraclasse, sugerimos aos alunos a qualificação adjetiva das personagens, sinalizando características que as protagonistas dos contos têm em comum. Esse exercício fomentará a leitura comparativa das personagens e a análise das personalidades de cada mulher das obras.

\section{Subtemática 6. Textos literários diversos de autoria feminina}

Encerrando as subtemáticas da sequência didática, escolhemos o trabalho com os textos literários diversos de autoria feminina para contemplar o talento, a linguagem, a técnica, a temática e os elementos de literariedade nas obras de escritoras de poesia e narrativa como Florbela Espanca, Auta de Souza, Cecília Meireles, Maria Valéria Rezende, Bruna Beber, Lygia 
Fagundes Telles.

Em quatro aulas, essa subtemática intenta reconhecer a legitimidade e o talento da autoria feminina, bem como a importância das escritoras literárias para o acervo literário brasileiro. Também é objetivo desse espaço da sequência didática a centralidade na aula de literatura de nomes de algumas escritoras brasileiras marginalizadas da literatura clássica.

A proposta de trabalho provoca, na primeira aula, a leitura das poesias "Primavera", de Florbela Espanca (2002), "Noites amadas", de Auta de Souza (2009), e "Motivo", de Cecília Meireles (2001), com o objetivo de, por meio do estudo dos elementos poéticos, conhecer a qualidade das obras de escritoras desconhecidas pelo cânone brasileiro.

Para a segunda aula dessa subtemática, a leitura do conto "Joaquim Maria", de Maria Valéria Rezende (2018), e a reflexão sobre a decisão tomada pela protagonista quanto à mudança de comportamento e de identidade foi pensada no intuito de apresentar a ideia de superioridade masculina no texto, a fim de transparecer a dificuldade da aceitação social quanto às habilidades da mulher.

$\mathrm{Na}$ terceira aula, propomos a leitura literária do texto "Romance em doze linhas", de Bruna Beber (2020), referenciando a qualidade da obra e a mensagem transmitida. Quanto à última aula, optamos pela leitura do conto "Venha ver o pôr-do-sol", de Lygia Fagundes Telles (2004), e debate sobre os perigos do fim de relacionamentos amorosos para as mulheres, violência e os crimes passionais.

Como atividade extraclasse, sugerimos aos alunos a construção de um texto, por meio da escrita criativa, evidenciando a mulher e o empoderamento, como os textos literários lidos e explorados em sala de aula, para posterior exposição na escola e publicação em meios de comunicação, como rádio ou jornal escolar, produção e divulgação de e-book, além de apresentação em projetos escolares. Para tanto, os alunos deverão ter como suporte a estrutura do conto e os elementos da narrativa.

Notamos, nessa proposta de sequência didática, a pluralidade de discussões, textos literários, autoras e leituras literárias cronologicamente distantes, porém com abordagens de problematizações comuns e atuais. Decerto, não se trata de uma sequência perfeita, tendo em vista suas fragilidades metodológicas, no entanto com temática atual sobre o empoderamento feminino e com um diversificado acervo literário. Acreditamos, dessa forma, na possibilidade do trabalho literário, que forme o leitor e que facilite a discussão e a centralidade da literatura feminina, até então, à margem do meio escolar.

\section{Considerações finais}

É fato que a luta feminina por direitos de equidade e igualdade é legítima e necessária para que as mulheres alcancem lugares que, durante muito tempo, eram predominantemente masculinos. Para isso, muitas figuras femininas derramaram sangue, a fim de conquistarem direitos que, atualmente, as mulheres gozam (o voto, o emprego remunerado, o uso da pílula anticoncepcional, a prática de esportes, entre outros). No entanto, os meios sócio educacionais devem suceder a luta de gênero iniciada há tantos anos. 
Desse modo, a proposta didática apresentada neste artigo se constitui como uma alternativa de insistência da luta feminina entre os jovens. Indubitavelmente, o empoderamento feminino torna-se uma temática muito conhecida entre este público, o que facilitou a escolha do tema para a construção da sequência didática.

A ideia de associação do empoderamento feminino à literatura favoreceu espaços de reflexão temática e de construção de experiências identitárias, a partir do debate e das narrativas e das personagens literárias que se aproximavam da mulher real, que vive no espaço ainda machista e precisa, ainda assim, impor sua voz, suas vontades e seus desejos.

É certo que a construção de uma sociedade igualitária e leitora não é tão fácil e rápida. De fato, as grandes mudanças de conceitos preestabelecidos e formados sobre a mulher e seu papel na sociedade não serão simples de serem rompidas, mas os primeiros passos precisam ser dados na escola e a educação literária se destaca como esse espaço democrático para todas as vozes sociais. É possível a formação do leitor crítico e disposto à reflexão das diferenças de gênero.

Acreditamos, portanto, na viabilidade da formação do leitor crítico e reflexivo por meio da aplicabilidade da sequência didática, uma vez que a proposta desenvolve uma temática atual, com a efetiva leitura de textos literários clássicos e contemporâneos atendendo à expectativa de horizontes de leitura dos jovens leitores para posterior trabalho de ampliação de suas leituras literárias.

Certamente, esse trabalho não esgota as inúmeras possibilidades metodológicas e de textos literários para o trabalho com o empoderamento feminino e a formação do leitor, mas se destaca como uma proposta que pode favorecer a leitura literária feminina do diverso e rico acervo de textos literários do Brasil.

\section{Referências}

AZEVEDO, Álvares de. Lira dos Vinte Anos. São Paulo: Martins Fontes, 1996.

BARATA, Paulo José. O que é ser mulher em uma obra de autoria feminina? Questionando valores masculinos e empoderamento feminino. In: CONGRESSO INTERNACIONAL ABRALIC, 14. Belém. Anais eletrônicos... 2015. Disponível em: www.abralic.org.br/anais/arquivos/2015_1456107161.pdf. Acesso em: 04 out 2018.

BATLIWALA, Srilatha. The meaning of women's empowerment: new concepts from action. In: GERMAIN, Adrienne; SEN, Gita; CHEN, Lincon C. (Eds.). Population policies reconsidered: health, empowerment and rights. Boston: Harvard University Press, 1994, p. $127-138$

BEBER, Bruna. Romance em doze linhas. Bruna Beber, 2020. Disponível em: http://brunabeber.com.br/portfolio/romance-em-doze-linhas/. Acesso em: 28 jul. 2020.

BORDINI, Maria da Glória; AGUIAR, Vera Teixeira de (Orgs.) A formação do leitor: alternativas metodológicas. Porto Alegre: Mercado Aberto, 1988. 
BRASIL. Conhecimentos de Literatura. In: BRASIL. Secretaria de Educação Básica. Ministérios da Educação. Orientações Curriculares para o Ensino Médio. Brasília: Ministério da Educação, Secretaria de Educação Básica, 2006, p. 49- 83. v. 1. (Linguagens, códigos e suas tecnologias). Disponível em: http://portal.mec.gov.br/seb/arquivos/pdf/book_volume_01_internet.pdf. Acesso em: 11 ago. 2016.

CANDIDO, Antonio. Literatura e sociedade. 9. ed. Rio de Janeiro: Ouro sobre Azul, 2004.

CARVALHO, Agenor Francisco de. Trajetória do empoderamento político da mulher brasileira. Monções, v. 3, n. 4, 2016.. Disponível em: http://seer.ufms.br/index.php/moncx/article/view/3131/2535. Acesso em: 20 set. 2018.

CHIZIANE, Paulina. Eu, mulher... Por uma nova visão de mundo. Revista do Núcleo de Estudos de Literatura Portuguesa e Africana, v. 5, n. 10, p. 199-205, abr. 2013.

COLASANTI, Marina. Contos de amor rasgados. Rio de Janeiro: Record, 2010.

COLOMER, Teresa. Andar entre livros: a leitura literária na escola. Trad. de Laura Sandroni. São Paulo: Global, 2007.

CORALINA, Cora. Melhores poemas. Organização de Darcy França Denófrio. 4. ed. São Paulo: Global. 2011.

COSSON, Rildo. Letramento literário: teoria e prática. 2. ed., $5^{\text {a }}$ reimp. São Paulo: Contexto, 2014.

DIAS, Gonçalves. Poesia completa e prosa escolhida. Rio de Janeiro: José Aguilar, 1959.

DOLZ, Joaquim; NOVERRAZ, Michèle; SCHNEUWLY, Bernard. Sequências didáticas para o oral e a escrita: apresentação de um procedimento. In: SCHNEUWLY, Bernard; DOLZ, Joaquim. Gêneros orais e escritos na escola. Trad. de Roxane Rojo e Glaís Sales Cordeiro. Campinas: Mercado das Letras, 2004, p. 81-108.

ESPANCA, Florbela. Poemas selecionados. Ciberfil Literatura Digital, 2002. Disponível em: http://www.dominiopublico.gov.br/download/texto/ph000240.pdf. Acesso em: 28/07/2020.

EVARISTO, Conceição. Insubmissas lágrimas de mulheres. 2. ed. Rio de Janeiro: Malê, 2016.

FAILLA, Zoara (Org.). Retratos da leitura no Brasil. Rio de Janeiro, Sextante, 2016. v. 4. Disponível em: http://prolivro.org.br/home/images/2016/RetratosDaLeitura2016_LIVRO_EM_PDF_FINAL_ COM_CAPA.pdf. Acesso em: 02 out. 2017.

FREITAS, Maria da Conceição Macedo de. Letramento literário em projetos do prêmio Mestres da Educação: reflexões e proposta. 2018. Dissertação (Mestrado Profissional em Formação de Professores) - Programa de Pós-Graduação em Formação de Professores, Universidade Estadual da Paraíba, Campina Grande, 2018.

JAUSS, Hans Robert. A história da literatura como provocação à teoria literária. Trad. de Sérgio Tellaroli. São Paulo: Ática, 1994. 
LEITE, Francisco Tarciso. Metodologia cientifica: métodos e técnicas de pesquisa: monografias, dissertações, teses e livros. Aparecida, SP: Ideias e Letras, 2008.

MEIRELES, Cecília. Antologia poética. 3.ed. Rio de Janeiro: Nova Fronteira, 2001.

MESQUITA, Lucimara Grando; DIAS, Rafaela Kelsen. "Ana Davenga" e "Beijo na face": empoderamento feminino e negro em personagens da antologia Olhos d'água. Revista Alpha, Patos de Minas, v. 18, n. 1, p. 164-173, jan./jul. 2017.

REZENDE, Maria Valéria. Mulheres do mundo. [Entrevista concedida a] Maria Laura Neves. Marie Claire, 01 fev. 2018.

REZENDE, Maria Valéria. Joaquim Maria. Tyrannus Melancholicus, 08 out. 2018. Disponível em: http://tyrannusmelancholicus.com.br/imprime.php?cid=11317\&sid=310. Acesso em: 28 jul. 2020.

ROUXEL, Annie. A tensão entre utilizar e interpretar na recepção de obras literárias em sala de aula: reflexão sobre uma inversão de valores ao longo da escolaridade. Trad. de Marcelo Bulgarelli. In: ROUXEL, Annie et al. (Orgs.) Leitura subjetiva e ensino de literatura. São Paulo: Alameda, 2013, p. 151-164.

SANTOS, Áurea Regina do Nascimento; MENDES, Algemira de Macedo. Configurações de gênero na narrativa de Paulina Chiziane: o empoderamento de vozes femininas. Palimpsesto, Rio de Janeiro, n. 22, p. 51-68, jan./jun. 2016. Disponível em: http://www.pgletras.uerj.br/palimpsesto/num22/dossie/palimpsesto22dossie04.pdf. Acesso em: 20 set. 2018.

SANTOS, Enedir Silva; GRÁCIA-RODRIGUES, Kelcilene. O tecer e o trajar: metáforas do empoderamento em dois contos de Marina Colasanti. Criação \& Crítica, n. 15, p. 160-174, dez. 2015. Disponível em: http://revistas.usp.br/criacaoeocritica. Acesso em: 20 set. 2018.

SARDENBERG, Cecília. Conceituando "Empoderamento" na perspectiva feminista. In: SEMINÁRIO INTERNACIONAL TRILHA DO EMPODERAMENTO DE MULHERES, 1, 2016, Salvador. Anais eletrônicos... Salvador: NEIM, UFBA, 2016. p. 1-12.

SOUZA, Auta de. Horto, outros poemas e ressonâncias: obras reunidas. Natal, RN: EDUFRNEditora da UFRN, 2009.

TELLES, Lygia Fagundes. Antologia: meus contos preferidos. Rio de Janeiro: Rocco, 2004.

OLIVEIRA, Gabriela Rodella de. As práticas de leitura literária de adolescentes e a escola: tensões e influências. 2013. 377f. Tese (Doutorado em Educação) - Faculdade de Educação, Programa de Pós-Graduação em Educação, Universidade de São Paulo, São Paulo, 2013.

ZABALA, Antoni. A prática educativa: como ensinar. Trad. de Ernani Rosa. Porto Alegre: ArtMed, 1998. 


\section{APÊNDICE \\ SEQUÊNCIA DIDÁTICA: A MULHER NA LITERATURA}

Subtemática 1: A mulher na literatura romântica

Número de aulas: 2 aulas

\section{Procedimentos metodológicos:}

- Leitura, em voz alta, pela professora dos textos "É ela! É ela! É ela! É ela!" e "Soneto", de Álvares de Azevedo (1996).

- Realizar um debate sobre a postura dos personagens masculinos nas poesias que assediam suas amadas, atentando-se aos fatos narrados nos textos poéticos.

- Iniciar a segunda aula com a retomada do debate sobre a postura abusiva do homem em determinados toques e carícias na mulher.

- Ler a poesia "Leito de folhas verdes", de Gonçalves Dias (1959), sugerindo, por meio do debate, o estudo do comportamento do eu-lírico feminino que deseja seu prazer sexual.

- Propor um diálogo acerca das características em comum dos textos românticos lidos, a fim de relacionar as personagens femininas nas poesias escolhidas.

- Tarefa para casa: Leitura do conto de fada "Cinderela", para trabalho em sala de aula.

Subtemática 2: Contos de fadas e contos modernos

Número de aulas: 1 aula

\section{Procedimentos metodológicos:}

- Iniciar a aula certificando a leitura do conto Cinderela proposta para sala.

- Realizar a leitura do texto “A moça tecelã”, de Marina Colasanti (2010), em voz alta e pela professora, com entonação apropriada para as falas dos personagens.

- Oportunizar espaço para o debate sobre as personagens femininas dos contos, solicitando dos alunos que apontem suas semelhanças e diferenças.

- Direcionar o debate para as posturas de submissão e empoderamento nas protagonistas dos contos lidos.

- Tarefa para casa: solicitar aos alunos a pesquisa do significado das palavras submissão e empoderamento.

Subtemática 3: Comportamentos femininos em Marina Colasanti

Número de aulas: 2 aulas

Procedimentos metodológicos:

- Realizar a leitura do conto "Para que ninguém a quisesse", de Marina Colasanti (2010), e incitar um rápido debate sobre o tema com o questionamento: O que faz uma mulher permitir situações de humilhação e alienação ao esposo? 
- Após, pedir a um aluno para ler, em voz alta, o texto "Quando já não era mais necessário", de Marina Colasanti (2010) e refletir sobre a postura da mulher nesta narrativa.

- Em segunda aula, retomar o debate sobre a postura feminina moderna e espontânea e solicitar a leitura do conto "Plano matrimonial", de Marina Colasanti (2010), referenciando a personagem que decide casar-se e escolhe seu esposo de acordo com sua vontade.

- Tarefa para casa: solicitar dos alunos um trabalho de entrevista com as mulheres responsáveis por eles, a fim de conhecerem suas opiniões sobre a atitude (ou a falta dela) da personagem feminina do texto "Para que ninguém a quisesse", de Marina Colasanti (2010).

Subtemática 4: A literatura e a mulher real

Número de aulas: 3 aulas

\section{Procedimentos metodológicos:}

- Iniciar a aula, retomando a exposição do resultado da atividade solicitada em aula anterior.

- Introduzir a leitura literária da poesia “Assim eu vejo a vida", de Cora Coralina (2011), e refletir sobre a mulher real, não ficcional, que sofre violência e misoginia em sua vida real.

- Nas duas aulas seguintes, realizar a leitura do testemunho Eu, mulher... por uma nova visão do mundo, de Paulina Chizianne (2013).

- Após a leitura, debater com os alunos sobre as dificuldades de ser mulher no dia a dia.

- Tarefa para casa: pedir aos alunos para escolherem uma profissional para questioná-la sobre as dificuldades de uma mulher na profissão.

Subtemática 5: Conceição Evaristo e o feminismo negro

Número de aulas: 4 aulas

\section{Procedimentos metodológicos:}

- Realizar em quatro aulas, a leitura de quatro contos de Conceição Evaristo (2016): "Aramides Florença"; "Natalina Soledad"; "Shirley Paixão"; e "Adelha Santana Limoeiro", solicitando, como atividade pós-leitura, a partilha de experiência de leitura dos estudantes, quanto ao enredo e aos comportamentos femininos das protagonistas das narrativas literárias lidas.

- Tarefa para casa: após a leitura dos contos, solicitar aos alunos a qualificação adjetiva das personagens, evidenciando aquilo que as protagonistas dos contos têm em comum.

Subtemática 6: Textos literários diversos de autoria feminina

Número de aulas: 4 aulas 


\section{Procedimentos metodológicos:}

- Na primeira aula, realizar a leitura dos seguintes textos poéticos: "Primavera", de Florbela Espanca (2002); "Noites amadas", de Auta de Souza (2009); e "Motivo", de Cecília Meireles (2001).

- Estudar os elementos poéticos dos textos lidos.

- Na segunda aula, ler, em voz alta, o conto "Joaquim Maria", de Maria Valéria Rezende (2018), refletindo, posteriormente à leitura, sobre a decisão tomada pela protagonista quanto à mudança de comportamento e de identidade.

- Na terceira aula, realizar a leitura literária do texto "Romance em doze linhas", de Bruna Beber (2020), referenciando a qualidade da obra e a mensagem transmitida pelo texto de autoria feminina.

- Na última aula da subtemática, oportunizar a leitura do conto "Venha ver o pôr-do-sol", de Lygia Fagundes Telles (2004) e favorecer debate pós-leitura sobre os perigos do fim de relacionamentos amorosos para as mulheres.

- Tarefa para casa: pedir aos alunos que, em grupos, construam, por meio da escrita criativa, um texto evidenciando a mulher e o empoderamento, como os textos literários lidos e explorados em sala de aula, para posterior exposição na escola.

\section{NOTAS DE AUTORIA}

Maria da Conceição Macedo de Freitas (profceicinhafreitas@gmail.com) é mestra em Formação de Professores, pela Universidade Estadual da Paraíba (UEPB), especialista em Língua, Linguística e Literatura, pelas Faculdades Integradas de Patos (FIP) e graduada em Licenciatura Plena em Letras pela mesma instituição. Atualmente trabalha na Escola Estadual de Ensino Fundamental e Médio Professora Margarida Remígio Loureiro, na cidade de Emas$\mathrm{PB}$, e se interessa pela leitura literária e o processo de letramento literário.

\section{Como citar esse artigo de acordo com as normas da revista}

FREITAS, Maria da Conceição Macedo de. Empoderamento feminino e literatura: uma proposta didática. Anuário de Literatura, Florianópolis, v. 25, n. 2, p. 203-221, 2020.

\section{Contribuição de autoria}

Não se aplica.

\section{Financiamento}

Não se aplica

Consentimento de uso de imagem

Não se aplica.

Aprovação de comitê de ética em pesquisa

Não se aplica.

\section{Licença de uso}


Este artigo está licenciado sob a Licença Creative Commons CC-BY. Com essa licença você pode compartilhar, adaptar, criar para qualquer fim, desde que atribua a autoria da obra.

\section{Histórico}

Recebido em: 07/04/2020

Revisões requeridas em: 15/06/2020

Aprovado em: 17/07/2020 